Canadian

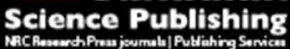

Environmental Reviews

Dossiers environnement

\title{
A Fundamental Dichotomy in Long-Chain Polyunsaturated Fatty Acid Abundance between and within Marine and Terrestrial Ecosystems
}

\begin{tabular}{|r|l|}
\hline Journal: & Environmental Reviews \\
\hline Manuscript ID & er-2016-0062.R1 \\
\hline Manuscript Type: & Review \\
\hline Complete List of Authors: & $\begin{array}{l}\text { Colombo, Stefanie; Ryerson University, Chemistry and Biology } \\
\text { Wacker, Alexander; University of Potsdam, Institute of Biochemistry and } \\
\text { Biology } \\
\text { Parrish, Christopher; Memorial University of Newfoundland, Ocean Sciences } \\
\text { Kainz, Martin; Biologische Station Lunz, WasserCluster } \\
\text { Arts, Michael; Ryerson University, Chemistry and Biology }\end{array}$ \\
\hline Keyword: & $\begin{array}{l}\text { climate change, food webs, omega-3, polyunsaturated fatty acids, trophic } \\
\text { ecology }\end{array}$ \\
\hline
\end{tabular}

\section{SCHOLARONE}

Manuscripts 


\title{
A Fundamental Dichotomy in Long-Chain Polyunsaturated Fatty Acid Abundance between and within Marine and Terrestrial Ecosystems
}

\author{
Stefanie M. Colombo ${ }^{1}$, Alexander Wacker ${ }^{2}$, Christopher C. Parrish ${ }^{3}$, \\ Martin J. Kainz ${ }^{4}$, Michael T. Arts ${ }^{1}$
}

${ }^{1}$ Department of Chemistry and Biology, Ryerson University, 350 Victoria Street, Toronto, Ontario, Canada

${ }^{2}$ Institute of Biochemistry and Biology, University of Potsdam, Am Neuen Palais 10, Potsdam, 14469 Germany

${ }^{3}$ Department of Ocean Sciences, Memorial University of Newfoundland, Marine Lab Road, St. John's, Newfoundland, Canada

${ }^{4}$ WasserCluster Lunz, Inter-university Centre for Aquatic Ecosystem Research, 3929 Lunz am See, Austria

Corresponding author: $\quad$ Stefanie M. Colombo

Department of Chemistry and Biology

Ryerson University

350 Victoria Street

Toronto Ontario Canada M5B 2K3

+1 (416) $979-5000$ ext. 3216

scolombo@ryerson.ca 
1 Abstract

Polyunsaturated fatty acids (PUFA), especially long-chain (i.e. $\geq 20$ carbons) polyunsaturated fatty acids (LC-PUFA), are fundamental to the health and survival of marine and terrestrial organisms. Therefore, it is imperative that we gain a better understanding of their origin, abundance, and transfer between and within these ecosystems. We evaluated the natural variation in PUFA distribution and abundance that exists between and within these ecosystems by amassing and analyzing, using multivariate and analysis of variance methods, $>3,000$ fatty acid (FA) profiles from marine and terrestrial organisms. There was a clear dichotomy in LCPUFA abundance between organisms in marine and terrestrial ecosystems, mainly driven by the $\mathrm{C}_{18}$ PUFA in terrestrial organisms and omega-3 (n-3) LC-PUFA in marine organisms. The PUFA content of an organism depended on both its biome (marine $v s$ terrestrial) and taxonomic group. Within the marine biome, the PUFA content varied among taxonomic groups. PUFA content of marine organisms was dependent on both geographic zone (i.e. latitude; and thus broadly related to temperature) and trophic level (a function of diet). The contents of n-3 LC-PUFA were higher in polar and temperate marine organisms than those from the tropics. Therefore, we conclude that, on a per capita basis, high latitude marine organisms provide a disproportionately large global share of these essential nutrients to consumers, including terrestrial predators. Our analysis also hints at how climate change, and other anthropogenic stressors might act to negatively impact the global distribution and abundance of n-3 LC-PUFA within marine ecosystems and on the terrestrial consumers that depend on these subsidies.

Keywords: climate change, food webs, omega-3, polyunsaturated fatty acids, trophic ecology 


\section{Introduction}

Fatty acids (FA) are the building blocks of structurally- and functionally-important lipid molecules (e.g. triacylglycerols, phospholipids) found in all organisms. Their production and distribution varies among plants and animals, and among biomes. A subset of FA, the long-chain (i.e. $\geq 20$ carbons long) polyunsaturated fatty acids (LC-PUFA), are known to have key physiological functions in all vertebrate organisms, specifically involved in supporting neurological development and function, cardiovascular health, visual acuity, growth, reproduction, and the immune system (Brenna et al. 2009; Simopoulos 2011; Swanson et al. 2012; Calder 2015). The LC-PUFA are also critically involved in maintaining structure and fluidity in cell membranes (Arts and Kohler 2009). In particular, eicosapentaenoic acid (EPA; 20:5n-3), docosahexaenoic acid (DHA; 22:6n-3), and arachidonic acid (ARA; 20:4n-6) have distinct and vital functions in vertebrates. EPA has anti-inflammatory effects, lowers the risk of cardiovascular disease, positively influences immune functions and defense against infections, and may protect against some cancers (reviewed by Calder 2015). DHA is directly involved in several processes in the brain including, neurotransmission, cell survival, and prevents neuroinflammation (and thereby mood and cognition, Bazinet and Laye 2014), and also acts as a precursor for docosatrienes, involved in anti-inflammation (Hong et al. 2003). ARA is also crucial for brain functioning, cell signalling, and is a precursor for endocannabinoids (Turcotte et al. 2015) and eicosanoids (Calder 2015). Thus, together, these three LC-PUFA form an important foundation for health and, by extension, survival in vertebrates.

There are large differences in the LC-PUFA composition of terrestrial and aquatic primary producers (Hixson et al. 2015; Twining et al. 2016). This inherent difference in LCPUFA production at the base of aquatic and terrestrial food webs has important physiological 
consequences for consumers. The LC-PUFA are mostly synthesized by primary producers at the base of aquatic food webs (e.g. diatoms, dinoflagellates, cryptophytes; Brett and Müller-Navarra 1997, Taipale et al. 2013; Galloway and Winder 2015). They are progressively consumed, and generally selectively retained, by other aquatic organisms higher up in the food chain (e.g. zooplankton, benthic invertebrates, molluscs, and fish; Dalsgaard et al. 2003; Iverson et al. 2004; Kainz et al. 2004; Budge et al. 2006; Hixson et al. 2015). The LC-PUFA are selectively retained at higher trophic levels; even small animals that have limited lipid storage capacity, under strong selection pressure retain these important compounds from their diet (Kainz et al. 2004;

Schlechtriem et al. 2006; Twining et al. 2016). While vertebrates can synthesize their own LCPUFA from their dietary precursors (ALA and LNA), the rate of synthesis is generally limited (Cook and McMaster 2004; Tocher et al. 2006); therefore, consuming EPA, DHA, and ARA preformed in the diet is highly advantageous for many vertebrates (Arts et al. 2001; Parrish 2009).

Freshwater ecosystems are known to be rich in n-3 PUFA, particularly EPA and DHA, in comparison with terrestrial ecosystems (Hixson et al. 2015; Twining et al. 2016). While the abundance and distribution of marine-derived LC-PUFA has been the focus of a plethora of studies for decades (e.g. Brockerhoff et al. 1963; Ackman et al. 1968; Dalsgaard et al. 2003; Budge et al. 2006; Arts et al. 2009; Parrish et al. 2013), a more global inventory of marine organism PUFA contents has yet to be compiled.

Aquatic organisms require cell membrane FA of varying chain lengths and numbers of double bonds to adapt to ambient water temperatures (Sinensky 1974; Cossins and Prosser 1978; Arts and Kohler 2009). This raises the question, is latitude (as a proxy for temperature) associated with distinct PUFA patterns in marine organisms and, if so, are there climate change implications? This distinction in PUFA content among marine latitudinal zones has been shown 
in certain taxa, such as phytoplankton (Hixson and Arts 2016), macrophytes (van Ginneken et al. 2011), and zooplankton (Kattner and Hagen 2009); however, it has not been documented considering the marine biome as a whole.

While it has been established that there is a distinct functional dichotomy in the LCPUFA production and abundance between freshwater and terrestrial ecosystems (Hixson et al. 2015), there is also a need to quantitatively establish this distinction between marine and terrestrial ecosystems. The n-3 and n-6 PUFA (ALA, EPA, DHA, and LNA and ARA, respectively) are of special interest due to their essentiality and physiological functions in organisms (Parrish 2009); therefore, we focused on these PUFA. The primary objective of this study is to quantify differences in PUFA among marine and terrestrial organisms, at varying trophic levels, to more rigorously document and quantify the distinct and natural variation in PUFA distribution and abundance that exists between and within these ecosystems.

\section{Methodological approach}

\section{Data collection}

Fatty acid data from marine and terrestrial organisms were collected from the primary, peer-reviewed, scientific literature. Articles were located and retrieved using the following citation indexing services: Google Scholar ${ }^{\odot}$, Web of Science ${ }^{\odot}$, and Scholars Portal ${ }^{\odot}$. The following search terms were used in combination with "fatty acids": marine, terrestrial, phytoplankton, macrophytes, zooplankton, bivalves, gastropods, annelids, echinoderms, crustaceans, cephalopods, fish, marine mammals, plants, insects, terrestrial mammals. In addition to the data derived from these searches we also used the marine phytoplankton FA profiles from Hixson and Arts (2016) and bird FA profiles from Galván et al. (2015). 
To qualify for inclusion in the data set, the data were required to be species-specific, sampled from either muscle tissue (the greatest tissue mass in the body) or the whole body, and the animals were not cultured (with the exception of cultured phytoplankton and macrophytes). Each study must have presented all FA of interest: ALA, LNA, EPA, DHA, ARA; as well as the sums of saturated FA (SFA), monounsaturated FA (MUFA), and PUFA (or total FA along with a complete list of FA to calculate these sums). The FA data must also have been presented as proportional data, i.e. individual FA as a percentage of total FA from total lipids (or the calculated mean of neutral and polar lipid); referred to as "FA content" hereafter. Although it would have been preferable to perform a data synthesis on FA contents expressed as massfractions (mg FA g ${ }^{-1}$ wet or dry weight tissue extracted), the majority of studies $(>75 \%)$ present FA data on a proportional basis (i.e. \%). A Grubb's outlier test was used to determine if there were significant outliers $(\mathrm{p}<0.05)$ for each FA within a particular group. If a significant outlier was detected (which occurred 8 times in the entire data set), the data entry was removed from the dataset.

\section{Dataset}

The FA data, for marine and terrestrial organisms, were sorted into 14 major taxonomic groups. The marine organisms comprised the following 11 taxonomic groups: phytoplankton, macrophytes, zooplankton, bivalves, gastropods, annelids, echinoderms, crustaceans, cephalopods, fish, birds, and marine mammals. The terrestrial taxa were sorted into 4 major taxonomic groups (plants, insects, birds, and terrestrial mammals). Complete FA data on other terrestrial vertebrates, such as reptiles and amphibians, are scarce in the literature, and thus were not included. In order to investigate patterns within either marine or terrestrial food webs, the above-mentioned groups were pooled, as follows, based on their approximate trophic position. 
114 Primary producers consisted of phytoplankton, macrophytes, and terrestrial plants.

115 Herbivores/omnivores consisted of annelids, bivalves, herbivorous/omnivorous crustaceans,

116 zooplankton, and herbivorous/omnivorous terrestrial mammals. Carnivores consisted of

117 cephalopods, carnivorous crustaceans, carnivorous fish, marine mammals, and carnivorous

118 terrestrial mammals. The marine FA data were also sorted by geographic origin. This was

119 determined by the location where the organism was sampled (as listed in the original primary

120 article), and which was characterized by three latitudinally-defined geographic zones: polar (90-

$12160^{\circ} \mathrm{N}$ and $\left.\mathrm{S}\right)$, temperate $\left(60-30^{\circ} \mathrm{N}\right.$ and $\left.\mathrm{S}\right)$, and tropical $\left(30^{\circ} \mathrm{N}\right.$ to $\left.30^{\circ} \mathrm{S}\right)$. In cases where algal

122 cultures were obtained from a collection, we used Algaebase (http://www.algaebase.org/) and/or

123 the World Register of Marine Species (WoRMS; http://www.marinespecies.org/index.php) to

124 obtain information on the known global distribution (range) of that algal species. Algae were

125 considered 'cosmopolitan' when they were listed as occupying two or more, of our three,

126 latitudinal zones.

127 Analysis of Variance zone, and/or trophic level could account for the variance in FA content among the organisms in our dataset. Biome (a fixed categorical variable) included 2 groups (marine or terrestrial).

131 Taxonomic group (also a fixed categorical variable) included 11 groups in the marine biome (see

132 above) and 3 groups in the terrestrial biome (see above). Latitudinal zone (a random categorical

133 variable) was characterized by three geographic regions (see above). Trophic level (a random

134 categorical variable) had three levels: primary producers, herbivore/omnivores, and carnivores,

135 as above. A nested ANOVA was used to determine the effect of latitudinal zone within

136 taxonomic group. 

PUFA) to determine the effects and/or interactions among biome, taxonomic group, latitudinal zone, and trophic position on FA content (Table 5). The categorical factors were considered to have significant effects on FA proportions and/or distributions when $\mathrm{p}<0.05$, and, where

142 significant differences occurred, treatment means were further differentiated using the Tukey HSD multiple comparison test, with Bonferroni corrections. The residuals from each model were examined to ensure there were no violations of model assumptions. Plots of residuals were evaluated for model assumptions: homogeneity of variance (plot of residuals $v s$ fitted values), normality (frequency of residuals, normal probability plot), and independence assumptions

147 (residuals $v s$ lag +1 residuals). Levene's test was also used to evaluate equal variances.

\section{Multivariate analyses}

All multivariate analyses were conducted using PRIMER-E (Plymouth Routines in Multivariate Ecological Research; PRIMER-E Ltd, version 7.0.10, Ivybridge, UK). Principal coordinates analysis (PCO) was used to visualize and quantify patterns observed among FA profiles (individual PUFA and the sums of SFA, MUFA, and PUFA) of organisms depending on their biome (marine or terrestrial), taxonomic group (see above), and approximate trophic level (see above). To evaluate the significance of the apparent biome, taxonomic group, and trophic level separation observed in the PCO, we used a one-way permutational multivariate analysis of variance (PERMANOVA) on the same FA dataset. The PCO was used on the entire data set of PUFA and FA groups (in both marine and terrestrial organisms), as well as the marine data subset, the terrestrial data subset, and the phytoplankton and fish data subsets. The FA vectors included all those in the analysis, listed above. 

The similarity in percentages (SIMPER) routine was used to differentiate FA profiles

161 based on biome and taxonomic group. The similarity coefficient in SIMPER ranges from 0 to

$162100 \%$ with the ends of the range representing the extreme possibilities, i.e. $\mathrm{S}=0 \%$ if two

163 samples are totally dissimilar and $\mathrm{S}=100 \%$ if two samples are totally similar. The non-metric

164 Bray-Curtis dissimilarity statistic was used to quantify the compositional dissimilarity between

165 samples in the PCO and SIMPER (Bray and Curtis 1957). This test delivers robust and reliable

166 dissimilarity results, and is one of the most commonly used metrics to explore relationships in

167 ecology, environmental sciences and related fields (Clarke and Warwick 2001). A permutation of

168 homogeneity of dispersions (PERMDISP) was used to test the homogeneity of multivariate

169 dispersions within groups. Significant differences in dispersion within taxonomic groups were

170 observed $(p=0.001)$; therefore, data were square root transformed prior to multivariate analysis

171 (Greenacre and Primicerio 2013; Hixson et al. 2015).

172

173

174

175

176

177

178

179

180

181

182

\section{Data synthesis results}

\section{Database}

A total of 3,072 FA profiles were collected from marine and terrestrial organisms which were subsequently divided into biomes (Table 1), taxonomic groups (Table 2), and latitudinal zones (in the case of marine organisms only; Table 3). The data set used in the analyses is provided in the Supplementary Data.

\section{ANOVA results}

Both biome and taxonomic group, and the interaction between them, significantly determined the FA content of organisms (Table S1). The single exception was that taxonomic group did not determine SFA; however, because the interaction between biome and taxonomic 
group was significant for SFA, taxonomic group could not be interpreted alone (Table S1). Trophic level determined PUFA and FA groups, as values tended to increase or decrease with increasing trophic level in both biomes (Table 4). This pattern was most striking in ALA, LNA, and DHA when compared between marine and terrestrial organisms (Fig. 1). ALA plus LNA decreased with increasing trophic level, but the magnitude of the change was different in marine and terrestrial ecosystems. DHA was not observed in terrestrial plants, and was also not recorded in insects (Table 1, Fig. 1). DHA content generally increased from primary producers to carnivores in marine ecosystems, with carnivores having significantly higher proportions than the other groups (Fig. 2a). ARA was higher in terrestrial organisms compared to marine organisms (Table 4). Within the marine ecosystem, herbivores/omnivores had higher EPA (Fig. 2b) and ARA contents (Fig. 2c) than primary producers and carnivores. ARA contents varied greatly among taxonomic groups within either ecosystem, and were notably high in macrophytes, gastropods, echinoderms, and insects (Table 1).

Latitudinal zone explained the variation in PUFA content for all PUFA and FA summary categories in marine organisms, except ALA and LNA (Table S2). Taxonomic group within marine environments also determined FA content (two-way ANOVA). Within each taxonomic group, latitudinal zone remained a significant factor in FA content of marine organisms, regardless of grouping (nested ANOVA; Table S3). In addition to latitudinal zone (except for ALA and LNA), individual PUFA content also depended on trophic level, and generally increased with higher trophic levels (Table S4, S5; Fig. 3). A nested ANOVA revealed that taxonomic group within each trophic level determines FA content $(p<0.05$ for all FA, except ALA; Table S6), not just trophic level alone ( $p>0.05$ for all FA). 


\section{Multivariate analyses results}

There was a clear separation, using PCO, between marine vs terrestrial individuals along PCO1 (Fig. 4), confirming that biome was a significant factor in the similarity matrix, according to the PERMANOVA design $(\mathrm{F}=1110.6 ; \mathrm{p}=0.001$; number of permutations $=999)$. The ordination explains $62.4 \%$ of the variation; PCO1 explained most of the total variation (40.3\%), and PCO2 explained another $22.1 \%$. The FA vectors along PCO1 indicated an association among EPA, DHA, and ARA with marine organisms, and ALA and LNA with terrestrial organisms. Along PCO2, SFA and MUFA showed an opposing relationship to PUFA (this was expected as these sums add up to $100 \%$ ), but did not divide the plot according to the biome factor imposed in this particular plot.

PCO explained $51.8 \%$ of the total variation $(\mathrm{PCO} 1=30 \%, \mathrm{PCO} 2=21.8 \%)$ in the FA content of marine organisms as a function of latitudinal zone. Taxonomic group $(\mathrm{F}=6.31 ; \mathrm{p}<$ $0.001)$, latitudinal zone $(\mathrm{F}=18.8 ; \mathrm{p}<0.001)$, and the interaction between taxonomic group and latitudinal zone $(\mathrm{F}=5.03 ; \mathrm{p}<0.001)$ were significant factors in the Bray-Curtis similarity matrix according to PERMANOVA (with 999 unique permutations). Using marine phytoplankton as a subset, the ordination explained $80.8 \%$ of the total variation, with PCO1 explaining most of the variation (52.4\%), and PCO2 the remainder (28.4\%). The PERMANOVA analysis revealed that latitudinal zone $(\mathrm{p}=0.002)$, taxonomic group $(\mathrm{p}=0.001)$, and the interaction between zone and group ( $\mathrm{p}=0.001)$ were significant factors in the Bray-Curtis similarity matrix. For marine fish

(Fig. 5), the ordination explained $74.3 \%$ of the total variation (PCO1 explained $55.7 \%$, and PCO2 explained $18.6 \%$ of the variation). Latitudinal zone was a significant factor in the BrayCurtis similarity matrix according to PERMANOVA $(F=16.0 ; p=0.001$; with 999 unique permutations). Within the terrestrial organism data set, PCO1 explained $40.5 \%$ of total variation, 
and PCO2 explained 19.5\% (Fig. 6). Taxonomic group was a significant factor in the BrayCurtis similarity matrix according to PERMANOVA ( $\mathrm{F}=113.2$; $\mathrm{p}=0.001$; with 995 unique permutations). The FA vectors along PCO1, DHA and ARA, indicated an association with birds and mammals, as opposed to plants and insects. Conversely, ALA, LNA, and PUFA were associated with plants and insects along PCO1.

SIMPER analysis revealed that within the marine data set, macrophytes and marine mammals were the most dissimilar pair based on their FA content (30.8\% dissimilar), while fish and zooplankton were the most similar pair (16.1\%). In both comparisons, MUFA caused the most variation between groups. Within taxonomic groups, phytoplankton were the most diverse in terms of FA content ( $71.8 \%$ similarity within the group) and marine mammals were the most similar ( $88.2 \%$ similarity within the group). Dispersion among groups was not homogenous ( $p=$ 0.001) according to PERMDISP, which is partially explained by unequal sample sizes among taxonomic groups, with some groups (such as phytoplankton) with a large number of samples (n $=505$ ) and large dispersion and higher variation. Within the marine data set, latitudinal zones were equally dissimilar (22.6-23.7\%). DHA caused the greatest dissimilarity between temperate and tropical marine organisms, while MUFA caused the most dissimilarity between polar and tropical or temperate marine organisms. Within the terrestrial data set, plants and mammals were the most dissimilar (34.5\%), followed by plants and birds (33.2\%), insects and mammals (30.6\%), plants and insects (29.3\%), insects and birds (29.1\%) and birds and mammals (25.8\%). LNA and ARA caused the most dissimilarities among all terrestrial groups compared. 


\section{Summary and Perspective}

\section{Data synthesis}

Our data synthesis, consisting of 3,072 FA profiles from marine and terrestrial organisms,

255 allowed us to uncover a striking dichotomy in the distribution and abundance of PUFA between

256 marine and terrestrial ecosystems. This contrast was primarily driven by the n-3 LC-PUFA (EPA, DHA) content in marine organisms, compared with terrestrial organisms (which contained higher levels of the $\mathrm{C}_{18}$ PUFA ALA and LNA; Fig. 4). Marine organisms also had higher total n3 PUFA contents, while terrestrial organisms had typically high total n-6 PUFA contents. While the FA content of marine organisms has been documented for hundreds of individual species, and the comparison between freshwater and terrestrial organisms has been established (Hixson et al. 2015), this is the first time FA composition in marine and terrestrial ecosystems has been compared in a comprehensive quantitative study.

Our data set represented 14 taxonomic groups distributed among marine and terrestrial ecosystems. While our data collection was as thorough as possible, FA profiles for marine organisms were much more prevalent in the literature than those for terrestrial organisms, and within marine organisms, certain taxa were better represented than others (often based on their relevance to human consumption; e.g. bivalves and fish). Grouping species together (i.e. by taxonomic group and/or trophic level) also introduced a degree of variability, as phylogeny is a known driver of FA content (Budge et al. 2002; Dalsgaard et al. 2003; Makhutova et al. 2011; Galloway and Winder 2015; Hixson et al. 2015). While we organized taxonomically and by trophic level in order to aid in the detection and interpretation of FA patterns among them, there is still marked variation in a single species within a taxonomic group because of an organism's specific habitat, feeding preferences, gender, life stage, etc., even when these species shared the 
same biome and had similar diets (according to trophic position). This introduced variation into our analysis. However, despite species differences, the variation within groups was minimal compared to the differences between groups, particularly between biomes. Our main conclusion is that a fundamental dichotomy exists in the relative abundance, and therefore global distribution, of PUFA between marine and terrestrial organisms.

\section{Dichotomy between ecosystems}

The difference in FA content between marine and terrestrial organisms is evident when observed visually in multivariate space (Fig. 4). This disparity is mainly driven by the LC-PUFA (EPA, DHA, and ARA) in marine organisms, and the $\mathrm{C}_{18}$ PUFA (ALA and LNA) in terrestrial organisms. This difference in FA content between the two ecosystems has its primary origin at the base of the food webs. In terrestrial ecosystems, ALA was the only n-3 PUFA recorded in primary producers (vascular plants) in our data set (although they are also known to produce other n-3 PUFA, such as 16:3n-3 and 18:4n-3: Dubois et al. 1997). By contrast, in marine ecosystems, primary producers (phytoplankton and macrophytes) predominantly contained $n-3$ LC-PUFA (EPA and DHA). In addition, our analyses revealed that marine primary producers synthesize, on average, $\sim 1.7 \times$ more n-3 PUFA (of the reduced subset of PUFA we analyzed here) than terrestrial primary producers. Our data analysis highlights that marine primary producers consist of $13-17 \%$ dietary n-3 LC-PUFA on average, which is available to subsequent consumers (Table 1), whereas such an n-3 LC-PUFA supply is entirely missing (at least in the plants we surveyed) from terrestrial primary producers. Further, we found that in marine organisms the n-3 PUFA dominate over n-6 PUFA; while the opposite is true for terrestrial organisms, which has also been observed when comparing terrestrial with freshwater organisms (Skjervold 1992; Koussoroplis et al. 2008; Hixson et al. 2015). Within each biome, taxonomic 
group played an important role, and so did the interaction between an organism's biome and their taxonomic group. Thus, the FA content of a particular organism depends on both an organism's location (land $v s$ ocean), and the taxonomic group to which it belongs.

The overall FA composition in organisms has been confirmed experimentally to also depend on their diet (Iverson et al. 1997; Lane et al. 2006; Koussoroplis et al. 2008; Torres-Ruiz et al. 2010) and has been reviewed (Iverson et al. 2004; Budge et al. 2006; Kelly and Scheibling 2012). We found that within each biome, individual PUFA tend to either increase or decrease as a function of an organism's trophic level, as well as habitat. For example, the sum of ALA and LNA generally decrease with increasing trophic level (Fig. 1), but are higher in terrestrial food webs than marine. On the other hand, DHA tended to increase with increasing trophic level, at least in the marine ecosystem (Figs. 1, 2,3). This result was also observed between terrestrial and freshwater organisms (Hixson et al. 2015). Interestingly, while SFA content depended on approximate trophic level, it was not different between biomes.

Similarly, to what was observed in our marine data set, other researchers have also observed that DHA was transferred and selectively retained in the aquatic food web, and generally increased in higher trophic levels (Kainz et al. 2004; Persson and Vrede 2006; Koussoroplis et al. 2008; Hixson et al. 2015; Twining et al. 2016). The essential PUFA are transferred along trophic levels at about twice the efficiency of bulk carbon (Gladyshev et al. 2011; Hartwich et al. 2013), and they are thereby generally retained, rather than diluted, in the biomass of organisms of higher trophic levels; a characteristic known in freshwater ecosystems (Gladyshev et al. 2013; Hixson et al. 2015; Twining et al. 2016). This is because DHA (and, to a lesser extent EPA) is minimally modified from ingestion to assimilation, and generally conserved in its original form to serve specific and important physiological purposes, rather than 
321 being catabolized and/or modified (Kainz et al. 2004; Twining et al. 2016). However, it is worth

322 noting that this pattern may be further modified by taxonomic affiliation, as organisms may share

323 a similar trophic position (e.g. cladocerans and copepods), but have markedly different DHA

324 contents. Ultimately, it is taxonomic group within each trophic level that is the most important

325 determinant, as shown in the nested ANOVA model. Conversely, $\mathrm{C}_{18}$ PUFA (ALA and LNA)

326 generally decrease with increasing trophic level (in both aquatic and terrestrial ecosystems),

327 which suggests that ALA and LNA are utilized either as precursors for the LC-PUFA or

328 catabolized, rather than being retained in tissues.

329 In terrestrial ecosystems, the EPA and DHA content in carnivores originated either

330 directly from aquatic food sources (see above) or is produced endogenously; although the rate of

331 synthesis from ALA is typically very low in vertebrates (Brenna et al. 2009; Domenichiello et al.

332 2015). Within the terrestrial ecosystem, the FA contents of mammals and birds were different

333 from terrestrial plants, on account of the difference in LNA (higher levels found in plants) and

334 DHA (not found in the plants in our data set; Fig. 6). The ability for vertebrates to either access

335 aquatic food sources, or modify ALA becomes important for survival. Therefore, we conclude

336 that terrestrial ecosystems are, in general, a much less important source of n-3 LC-PUFA

337 production than aquatic ecosystems, and that aquatic organisms (both marine and freshwater),

338 through a variety of pathways (Gladyshev et al. 2009), provide an important nutrient subsidy to

339 terrestrial organisms. The availability of rich sources of EPA and DHA is critical for many

340 terrestrial vertebrates, and the timing and quantity may be important as well. For example,

341 shorebirds are known to gorge on n-3 LC-PUFA marine resources for long distance migration,

342 i.e. n-3 LC-PUFA are used as 'performance enhancing substances' to prepare muscles for

343 migration (Maillet and Weber 2006; Guglielmo 2010). 


\section{Fatty acid dynamics in food webs}

The LC-PUFA have different physiological functions, may be metabolized and incorporated into tissues differently, and may vary in terms of importance in nutritional requirements for different species (Emery et al. 2016). We found that individual PUFA contents varied as a function of the biome of the organism and/or their approximate trophic position in the food chain. Generally, we found that FA tended to increase or decrease with increasing trophic level (Fig. 2), although this was not always the case. For example, relative EPA content increased from marine primary producers to herbivores/omnivores, but decreased from herbivores/omnivores to carnivores. Some of the herbivores/omnivores in our marine data set were zooplankton, which have been shown to exhibit an EPA-retentive metabolism (Kainz et al. 2004; Wacker and Martin-Creuzburg 2007; Hartwich et al. 2013). EPA is highly retained in zooplankton, whereas DHA is highly retained in most fish (e.g. salmonids; Kainz et al. 2004), which explains the different relationships we observed between EPA and DHA in our data. In fish, for example, there is increasing evidence to support the observation that EPA is preferentially catabolized or further converted to DHA (e.g. in salmonids; Murray et al. 2014) rather than spared and retained in tissues, and as such, EPA appears to be generally more dispensable compared to DHA (Trushenski et al. 2012; Glencross et al. 2015; Emery et al. 2016). This was observed in our dataset which documented a decrease in EPA content in carnivores. It has been suggested that DHA (and ARA), are the primary drivers of LC-PUFA essentiality in some fish species (Trushenski et al. 2012; Rombenso et al. 2016). This may be the case in other aquatic vertebrates and semi-aquatic mammals as well (Koussoroplis et al. 2008), as we observe selective retention in DHA up to carnivores, coupled with a significant drop in EPA content. Therefore, it appears that EPA and DHA are required in different proportions by different 
consumers, and together are not necessarily progressively retained from primary producers up to carnivores, although this is highly dependent on species.

\section{Fatty acid abundance and distribution within marine ecosystems}

The diversity of organisms in our data set allowed us to take a quantitative approach in defining similarities and differences in the abundance and distribution of FA within the marine ecosystem. Marine macrophytes and marine mammals had the most dissimilar FA profiles, while fish and zooplankton had the most similar FA profiles. In both comparisons, MUFA was the underlying source of most of the variation between groups. This distinction is important, as individual MUFA are often recognized as biochemical markers in marine food webs, and are frequently used to quantitatively document predator-prey interactions (Iverson et al. 2009). Beyond diet, taxonomy is an important factor that defines FA content in marine organisms (Gladyshev et al. 2013; Galloway and Winder 2015). Species grouped in similar, yet broad taxonomic classifications did not necessarily possess the same FA content as one another. For example, we found that phytoplankton were the most diverse group in terms of FA content. Dispersion among taxonomic groups was not homogenous, which can be partially explained by unequal sample sizes, with some taxa (such as phytoplankton), that had a large number of samples, showing a large dispersion and higher variation. Ultimately, we found that assuming the trophic level of an organism (as a function of diet, as shown by Iverson et al. 2004; Budge et al. 2006) could be used as a tool to roughly estimate FA content. However, it is taxonomic group within each trophic level that is a more important determinant (Galloway and Winder 2015), as shown in the nested ANOVA model. 


\section{Fatty acid differences in marine ecosystems defined by latitude}

Temperature directly influences metabolism, functioning, and survival in aquatic organisms (Gaston 2003). In an attempt to maintain physiological homeostasis when faced with temperature changes (Clarke 2003), ectotherms may change the structure of their cell membrane by modifying FA chain length and degree of unsaturation in membrane lipids to maintain a desired level of order (fluidity) in cell membranes (Sinensky 1974; Guschina and Harwood 2006; Arts and Kohler 2009). In order to maintain fluidity in cold waters, ectotherms tend to retain or increase the content of membrane PUFA, as the double bonds enhance the ability of FA to “bend” and increase membrane fluidity (Hazel 1995; Arts and Kohler 2009; Sperfeld and Wacker 2012; Parrish 2013). Therefore, using latitude (as a proxy for habitat temperature) to quantitatively define the FA content of marine organisms was of interest. We found that geographic zone, taxon, and trophic level synergistically determined the FA content of marine organisms. The $\mathrm{C}_{18}$ PUFA (ALA and LNA) content in marine organisms did not differ by geographic zone. These PUFA are essential to animals regardless of latitude; however, they differed quantitatively among taxa and trophic level.

Generally, it is assumed that LC-PUFA, especially EPA and DHA, are less prevalent or abundant in tropical marine ecosystems compared to polar marine ecosystems, where EPA and DHA are known to be in rich and abundant supply (Lands 1982; Broadhurst et al. 2002). Tropical organisms tend to possess FA profiles that are somewhat different from those of temperate and polar regions (Ahlgren et al. 2009; Iverson et al. 2009). For example, in polar oceans, marine organisms characteristically contain relatively high levels of MUFA (particularly 20:1 and 22:1), which are often regarded as biomarkers of zooplankton, such as krill and copepods (Brett et al. 2009) These MUFA are routinely transferred to higher trophic level 
413 organisms. This was observed in the polar marine organisms in our data set (Table 3), including

414 fish (Fig. 3), relative to tropical and temperate organisms.

We found that the relative proportion of n-3 LC-PUFA, total MUFA, and total PUFA

416 were higher in organisms located in polar regions than those in tropical regions. This aligns with

417 the hypothesis that cold-water ectotherms organize long-chain, unsaturated FA to maintain

418 membrane fluidity in order to inhabit cold waters (Sinensky 1974; Arts and Kohler 2009). For

419 this reason, having elevated n-3 LC-PUFA levels may be a mechanism used to survive in polar

420 regions, where organisms typically live at temperatures near the freezing point for much of the

421 year (Thomas and Dieckmann 2002). Both in macrophytes (van Ginneken et al. 2011) and

422 microalgae (Boelen et al. 2013; Hixson and Arts 2016), PUFA content and degree of

423 unsaturation in polar oceans were higher than in tropical oceans. Conversely, total SFA and ARA

424 increase in marine organisms going from polar to tropical regions (assuming increasing

425 temperature); a result also observed in a large data synthesis of phytoplankton (Hixson and Arts

426 2016) and macrophytes (van Ginneken et al. 2011). It is important to note that we did not

427 consider depth as a factor within each latitudinal zone for all marine data, thus tropical organisms

428 inhabiting deep waters may be subject to low temperatures, potentially increasing their n-3 LC-

429 PUFA content. While we did not specifically account for this in our analysis, we estimated that

430 our dataset of marine fish contained relatively equal proportions of deep-sea fish among the three

431 latitudinal zones (polar 25.6\%, temperate 29.2\%, tropical 32.5\%). Thus, our dataset did not have

432 an undue bias towards "colder-water" deep-sea fish in tropical zones. Further, despite the slightly

433 higher contribution of deep-sea fish in the tropical zone (potentially increasing the n-3 LC-PUFA

434 content in tropical fish), the difference in LC-PUFA content among latitudinal zones is still 
435 clearly evident. Thus our analyses yielded a conservative estimate of the observed differences

436 among fishes from different latitudinal zones, and especially between polar and tropical fish.

\section{Fish in polar, temperate, and tropical waters}

Fish were of particular interest due to their importance as a protein source and ultimately the main source of pre-formed LC-PUFA for terrestrial vertebrates (including humans). Fish represent a major vector (subsidy) in the transfer of LC-PUFA from marine to terrestrial ecosystems (Gladyshev et al. 2009, 2013). Furthermore, fish and shellfish production in marine ecosystems will likely remain a key source of EPA and DHA for humans. Therefore, it is important to identify and conserve geographic areas that have exceptionally high n-3 LC-PUFA production and subsequent retention in fish. We found that latitudinal geographic zone significantly determined FA content in fish in multivariate space (Fig. 5). 
We observed separation of fish in polar and tropical marine zones, with fish in temperate

459

460

461

462

463

464

465

466

467

468

469

470

471

472

473

474

475

476

477

478

479

zones in between and dispersed within fish in tropical and polar zones, which created a

latitudinal gradient (Fig. 5). Generally, tropical ecosystems contain organisms with FA profiles

that are different from those in temperate and polar ecosystems (Iverson et al. 2009), and warm-

water fish contain less EPA and DHA, and more ARA compared to cold-water fish (Lands 1982;

Broadhurst et al. 2002; Kolakowska et al. 2006). The high MUFA levels we observed in polar

fish are likely a biomarker of zooplankton (copepods), as this taxonomic group is an important

link between lower and higher trophic levels (Parrish 2013). Typical of tropical ecosystems, prey

throughout these systems generally contain relatively high levels of n-6 LC-PUFA, and very low levels of MUFA (Iverson et al. 2009).

We found that fish in polar and temperate marine zones provide the highest nutritional value for human consumption in terms of n-3 LC-PUFA content. Ironically, some of the most striking impacts of global climate change have been observed in polar oceans (Hoegh-Guldberg and Bruno 2010), and it is known that these regions are particularly sensitive to changes in temperature (Smetacek and Nichol 2005). At the base of marine food webs, the distribution, abundance, and productivity of primary producers (i.e. phytoplankton) are changing in response to eutrophication, warming, acidifying, and stratifying oceans, and the effects of these systemic changes can cascade through food webs (Polovina et al. 2008; Doney et al. 2009). An increase in water temperature due to climate change is predicted to result in decreased proportions of EPA and DHA in a variety of organisms including phytoplankton (Hixson and Arts 2016), copepods (Werbrouck et al. 2016), and albacore tuna (Parrish et al. 2015), as a result of cellular adaptation (homeoviscous adaption) to warming waters. This indicates that the impact of warming waters 
480 481 482 483 484 485 486 487 488 489 490 491 492 493 494 495 496 497 498 499 500 501 502

may alter FA content in consumers, not only through nutrient transfer, but also through their own biochemical response to temperature (Werbrouck et al. 2016).

Compounding these effects, climate change can also shift the normal geographic distribution of fish, and other species' populations, as they adapt to current ambient conditions (Stachowicz et al. 2002, Gamito et al. 2015). A rising number of non-polar species are already expanding their ranges into more polar areas (Hoegh-Guldberg and Bruno 2010). Tropical species are predicted to expand toward temperate regions, and temperate species in turn will move into polar regions (Cheung et al. 2009; Vinagre et al. 2011). The dominance of lipid-rich species (with high n-3 LC-PUFA contents) at high latitudes will probably decrease in response to this shift (Gamito et al. 2015). These shifts in population distribution and changes in FA quantity and quality in response to warming temperatures can ultimately affect the health-benefits of commercially-relevant species that inhabit the most sensitive regions to climate change.

\section{Implications for consumers}

Vertebrates (and most aquatic invertebrates) require DHA (and EPA to some extent) for optimal functioning (Arts et al. 2009; Calder 2015). Endogenous biosynthesis from ALA (or from other precursors, such as EPA or 22:5n-3) is generally limited in most vertebrates, including humans (Brenna et al. 2009). As our data synthesis shows that primary producers in marine and terrestrial ecosystems exert a high level of control over the distribution of EPA and DHA among higher trophic level organisms in their respective food webs. Ultimately EPA and DHA synthesized by aquatic primary producers make their way, by various vectors, to terrestrial organisms (including humans). These n-3 LC-PUFA are not produced in quantity by most plants in terrestrial food webs therefore, preformed EPA and DHA are generally not available to consumers from this source. While terrestrial predators usually cannot obtain EPA and DHA 
503 from terrestrial plants, ultimately they can be derived from terrestrial ALA and subsequently

504 bioconverted, either by the predators themselves, or by their prey. This indirect route has

505 energetic costs, in terms of trophic efficiency, as well as the amount of ALA (from plants) and n-

5063 LC-PUFA derived from their prey, because n-3 PUFA are not as prevalent in terrestrial

507 organisms compared to their aquatic counterparts. Thus the supply of preformed EPA and DHA

508 from aquatic organisms generally provides a more abundant and more efficient source of n-3 LC-

509 PUFA to terrestrial animals that have access to aquatic ecosystems (Gladyshev et al. 2009,

510 2013). Consumers that do not have access to aquatic resources, particularly primary consumers,

511 have undoubtedly faced strong selection pressure to modify ALA and LNA into LC-PUFA, as

512 the ability to synthesize the LC-PUFA is likely related to the inverse of access to these LC-

513 PUFA (Hixson et al. 2015).

514 Conclusions

515 We have illustrated a fundamental dichotomy in PUFA abundance and distribution

516 between marine and terrestrial ecosystems. Biome, taxonomy, and trophic level defined FA

517 content of organisms between (and within) ecosystems. Individual n-3 and n-6 PUFA showed

518 different relationships among trophic levels, indicating that EPA, DHA, and ARA are

519 functionally different, and are likely retained or catabolized differently as a function of taxonomy

520 and diet. In marine ecosystems, the n-3 LC-PUFA were higher in polar and temperate organisms

521 than those in the tropics. In particular, fish located in polar and temperate latitudes feature higher

522 levels of n-3 LC-PUFA than those in the tropics. Therefore, we conclude that cool water fish in

523 particular provide an important resource (i.e. essential n-3 LC-PUFA) to many consumers,

524 including terrestrial predators. Climate warming and other anthropogenic influences threaten LC-

525 PUFA production in marine ecosystems in a variety of ways. These factors include increasing 
526 water temperatures and its effect on homeoviscous adaptation of cell membranes, biological

527 impacts such as eutrophication (which leads to algal communities being dominated by LC-

528 PUFA-impoverished cyanobacteria), novel species assemblages (i.e. redistribution of species),

529 overfishing (Hoegh-Guldberg and Bruno 2010), and increased absorption of anthropogenic $\mathrm{CO}_{2}$

530 leading to ocean acidification (Bermúdez et al. 2015). Ultimately these human-induced changes

531 can impact the production, distribution, and transfer of EPA and DHA within the marine

532 ecosystem, and may eventually reduce their transfer (subsidy) to terrestrial ecosystems.

533 Therefore, in light of these effects it is becoming increasingly imperative to conserve our marine

534 resources so as to sustain adequate levels of n-3 LC-PUFA for our health, and for the health of

535 all animals on this planet.

536 Acknowledgements

537 Funding for this work was provided by Ryerson University and by a Natural Sciences and

538 Engineering Research Council Discovery Grant (\#04537-2014 to MTA). AW was supported by

539 the German Research Foundation (DFG 2445/8-1) and MJK by the Austrian Science Fund (FWF

540 project I 1057-B25). The authors thank Alina Tsimbaliouk, Ryerson University, Department of

541 Chemistry and Biology, and Jennifer Weise, Potsdam University, Theoretical Aquatic Ecology

542 and Ecophysiology, for assistance in data collection. Please note that Stefanie M. Colombo was

543 listed in previous publications (from 2010-2015) as Stefanie M. Hixson. 


\section{Figures and Tables}

Table 1 . Fatty acid content ( $\%$ total fatty acids) of marine and terrestrial organisms (mean \pm standard error).

\begin{tabular}{|c|c|c|c|c|c|c|c|c|c|c|c|}
\hline Taxonomic group & LNA & ALA & ARA & EPA & DHA & $\sum$ SFA & $\sum$ MUFA & $\sum$ PUFA & $\sum n-3$ FA & $\sum n-6$ FA & DHA/EPA \\
\hline \multicolumn{12}{|l|}{ Marine $(n=2,063)$} \\
\hline Phytoplankton $(\mathrm{n}=504)$ & $2.5 \pm 0.2$ & $3.5 \pm 1.0$ & $0.8 \pm 0.1$ & $11.9 \pm 0.4$ & $5.2 \pm 0.3$ & $37.0 \pm 0.7$ & $25.3 \pm 0.5$ & $35.4 \pm 0.7$ & $20.8 \pm 1.1$ & $3.3 \pm 0.2$ & $3.6 \pm 0.5$ \\
\hline Macrophytes $(\mathrm{n}=191)$ & $6.2 \pm 0.4$ & $6.6 \pm 0.5$ & $8.6 \pm 0.5$ & $13.2 \pm 1.0$ & $0.2 \pm 0.1$ & $35.0 \pm 1.0$ & $19.8 \pm 0.7$ & $44.7 \pm 1.1$ & $20.1 \pm 0.1$ & $14.8 \pm 0.6$ & $0.05 \pm 0.01$ \\
\hline Zooplankton $(\mathrm{n}=139)$ & $1.7 \pm 0.1$ & $1.6 \pm 0.1$ & $1.2 \pm 0.2$ & $16.2 \pm 0.5$ & $15.2 \pm 0.7$ & $24.9 \pm 0.8$ & $32.1 \pm 1.5$ & $44.6 \pm 1.2$ & $33.0 \pm 1.1$ & $2.9 \pm 0.2$ & $1.0 \pm 0.05$ \\
\hline Bivalves $(n=242)$ & $2.1 \pm 0.1$ & $1.8 \pm 0.1$ & $2.4 \pm 0.1$ & $14.6 \pm 0.5$ & $11.9 \pm 0.5$ & $30.7 \pm 0.9$ & $20.5 \pm 0.6$ & $46.2 \pm 0.9$ & $28.3 \pm 0.8$ & $4.4 \pm 0.2$ & $1.1 \pm 0.1$ \\
\hline Gastropods $(\mathrm{n}=118)$ & $2.6 \pm 0.2$ & $2.4 \pm 0.2$ & $7.8 \pm 0.5$ & $10.0 \pm 0.8$ & $2.5 \pm 0.5$ & $30.9 \pm 0.8$ & $23.5 \pm 0.6$ & $41.6 \pm 1.0$ & $14.9 \pm 1.0$ & $10.4 \pm 0.5$ & $0.8 \pm 0.2$ \\
\hline Annelids $(\mathrm{n}=48)$ & $5.2 \pm 1.0$ & $1.9 \pm 0.3$ & $2.2 \pm 0.2$ & $9.7 \pm 1.0$ & $3.3 \pm 0.6$ & $24.8 \pm 0.9$ & $32.8 \pm 1.6$ & $37.6 \pm 1.8$ & $14.9 \pm 1.3$ & $7.4 \pm 1.0$ & $0.3 \pm 0.1$ \\
\hline Echinoderms $(\mathrm{n}=106)$ & $2.6 \pm 1.2$ & $1.4 \pm 0.2$ & $11.2 \pm 0.7$ & $13.0 \pm 0.8$ & & $26.2 \pm 1.1$ & & $41.4 \pm 1.5$ & $18.2 \pm 1.0$ & $13.8 \pm 1.4$ & $0.8 \pm 0.4$ \\
\hline Crustaceans $(\mathrm{n}=153)$ & $1.9 \pm 0.2$ & $0.6 \pm 0.1$ & $4.6 \pm 0.3$ & $15.3 \pm 0.6$ & $10.7 \pm 0.5$ & $24.2 \pm 0.8$ & $28.7 \pm 0.9$ & $39.2 \pm 1.1$ & $26.7 \pm 0.9$ & $6.5 \pm 0.4$ & $0.8 \pm 0.04$ \\
\hline Cephalopods $(\mathrm{n}=118)$ & $0.6 \pm 0.1$ & $0.3 \pm 0.0$ & $3.3 \pm 0.3$ & $12.8 \pm 0.4$ & $23.9 \pm 0.9$ & $28.2 \pm 0.9$ & $16.3 \pm 1.1$ & $44.7 \pm 1.4$ & $37.0 \pm 1.2$ & $4.0 \pm 0.3$ & $1.9 \pm 0.1$ \\
\hline Fish $(\mathrm{n}=239)$ & $1.5 \pm 0.1$ & $0.9 \pm 0.1$ & $2.2 \pm 0.2$ & $7.7 \pm 0.3$ & $17.7 \pm 0.6$ & $29.2 \pm 0.5$ & $34.0 \pm 0.8$ & $34.9 \pm 0.8$ & $26.3 \pm 0.7$ & $3.7 \pm 0.2$ & $2.9 \pm 0.1$ \\
\hline Mammals $(\mathrm{n}=205)$ & $1.6 \pm 0.1$ & $0.7 \pm 0.1$ & $1.0 \pm 0.3$ & $5.4 \pm 0.2$ & $7.9 \pm 0.3$ & $18.1 \pm 0.4$ & $55.6 \pm 0.7$ & $27.5 \pm 1.1$ & $14.1 \pm 0.4$ & $2.6 \pm 0.3$ & $1.7 \pm 0.1$ \\
\hline \multicolumn{12}{|l|}{ Terrestrial $(n=1,009)$} \\
\hline Plants $(n=410)$ & $38.4 \pm 1.0$ & $11.8 \pm 0.8$ & $0.5 \pm 0.1$ & - & - & $20.9 \pm 0.8$ & $26.6 \pm 0.9$ & $50.5 \pm 1.0$ & $11.8 \pm 0.8$ & $38.9 \pm 1.0$ & - \\
\hline Insects $(n=389)$ & $15.4 \pm 0.7$ & $13.4 \pm 0.8$ & $16.5 \pm 2.9$ & $1.3 \pm 0.5$ & - & $35.4 \pm 1.0$ & $35.8 \pm 0.9$ & $28.8 \pm 1.0$ & $14.7 \pm 0.1$ & $31.9 \pm 2.6$ & - \\
\hline Birds $(\mathrm{n}=107)$ & $9.96 \pm 0.5$ & $0.99 \pm 0.1$ & $8.18 \pm 0.3$ & $0.14 \pm 0.0$ & $3.75 \pm 0.2$ & $48.4 \pm 0.5$ & $25.6 \pm 0.7$ & $26.0 \pm 0.6$ & $6.3 \pm 0.2$ & $19.8 \pm 0.6$ & $37.5 \pm 2.1$ \\
\hline Mammals (n=193) & $12.5 \pm 0.8$ & $5.6 \pm 1.2$ & $2.6 \pm 0.5$ & $0.9 \pm 0.1$ & $1.8 \pm 0.3$ & $40.3 \pm 1.1$ & $36.8 \pm 1.1$ & $22.5 \pm 1.2$ & $8.3 \pm 0.6$ & $15.1 \pm 0.7$ & $2.1 \pm 0.4$ \\
\hline
\end{tabular}


Table 2 . Fatty acid content ( $\%$ total fatty acids) of marine and terrestrial primary producers, herbivores/omnivores, and carnivores (mean \pm standard error). Different superscripts in the same column (i.e. for each fatty acid) indicates significant differences among trophic levels within each biome.

\begin{tabular}{|c|c|c|c|c|c|c|c|c|c|c|c|}
\hline Trophic level & ALA & LNA & ARA & EPA & DHA & $\sum$ SFA & $\sum$ MUFA & $\sum$ PUFA & $\sum n-3$ FA & $\sum n-6$ FA & DHA/EPA \\
\hline \multicolumn{12}{|l|}{ Marine } \\
\hline Primary producers $^{1}$ & $4.83 \pm 0.8 \mathrm{a}$ & $3.59 \pm 0.2 \mathrm{a}$ & $3.17 \pm 0.2 b$ & $12.3 \pm 0.4 \mathrm{~b}$ & $3.84 \pm 0.2 \mathrm{c}$ & $36.4 \pm 0.6 \mathrm{a}$ & $23.7 \pm 0.4 \mathrm{c}$ & $38.1 \pm 0.6 \mathrm{~b}$ & $23.7 \pm 0.4 b$ & $6.85 \pm 0.3 \mathrm{a}$ & $2.5 \pm 0.3 \mathrm{a}$ \\
\hline Herbivores/omnivores $^{2}$ & $1.61 \pm 0.1 \mathrm{~b}$ & $2.34 \pm 0.2 b$ & $4.54 \pm 0.2 \mathrm{a}$ & $13.8 \pm 0.3 \mathrm{a}$ & $9.18 \pm 0.3 b$ & $27.5 \pm 0.4 \mathrm{~b}$ & $26.3 \pm 0.4 b$ & $42.9 \pm 0.5 \mathrm{a}$ & $26.3 \pm 0.5 b$ & $6.88 \pm 0.3 \mathrm{a}$ & $0.9 \pm 0.1 b$ \\
\hline Carnivores $^{3}$ & $0.67 \pm 0.0 \mathrm{~b}$ & $1.37 \pm 0.1 \mathrm{c}$ & $2.09 \pm 0.2 \mathrm{c}$ & $8.18 \pm 0.2 \mathrm{c}$ & $15.4 \pm 0.4 \mathrm{a}$ & $25.1 \pm 0.4 \mathrm{c}$ & $37.8 \pm 0.6 \mathrm{a}$ & $34.4 \pm 0.6 \mathrm{c}$ & $38.1 \pm 0.6 \mathrm{a}$ & $3.45 \pm 0.2 b$ & $2.2 \pm 0.1 \mathrm{a}$ \\
\hline \multicolumn{12}{|l|}{ Terrestrial } \\
\hline Primary producers $^{1}$ & $11.1 \pm 0.8 \mathrm{a}$ & $38.4 \pm 1.0 \mathrm{a}$ & $0.52 \pm 0.1 \mathrm{c}$ & $0.00 \pm 0.0 \mathrm{c}$ & $0.00 \pm 0.0 \mathrm{~b}$ & $20.8 \pm 0.8 \mathrm{c}$ & $52.5 \pm 2.1 \mathrm{a}$ & $50.3 \pm 1.0 \mathrm{a}$ & $26.6 \pm 0.9 \mathrm{c}$ & $36.4 \pm 1.5 \mathrm{a}$ & - \\
\hline Herbivores/omnivores $^{2}$ & $8.72 \pm 0.5 b$ & $14.1 \pm 0.5 b$ & $8.07 \pm 0.8 \mathrm{a}$ & $0.62 \pm 0.1 \mathrm{~b}$ & $3.12 \pm 0.2 \mathrm{a}$ & $39.2 \pm 0.7 \mathrm{a}$ & $33.4 \pm 0.7 \mathrm{~b}$ & $27.5 \pm 0.7 \mathrm{~b}$ & $33.4 \pm 0.7 \mathrm{~b}$ & $18.4 \pm 0.7 \mathrm{~b}$ & $5.0 \pm 0.2 \mathrm{a}$ \\
\hline Carnivores $^{3}$ & $6.92 \pm 3.6 \mathrm{c}$ & $7.87 \pm 0.9 \mathrm{c}$ & $2.35 \pm 0.7 b$ & $2.39 \pm 0.4 \mathrm{a}$ & $3.25 \pm 0.4 \mathrm{a}$ & $25.4 \pm 1.6 \mathrm{~b}$ & $26.6 \pm 0.9 \mathrm{c}$ & $20.6 \pm 1.2 \mathrm{c}$ & $52.5 \pm 0.2 \mathrm{a}$ & $10.2 \pm 1.4 \mathrm{c}$ & $1.6 \pm 0.2 b$ \\
\hline Biome term (p-value) & $<0.001$ & $<0.001$ & $<0.001$ & $<0.001$ & $<0.001$ & 0.819 & $<0.001$ & $<0.001$ & $<0.001$ & $<0.001$ & $<0.001$ \\
\hline Trophic term (p-value) & $<0.001$ & $<0.001$ & $<0.001$ & $<0.001$ & $<0.001$ & $<0.001$ & $<0.001$ & $<0.001$ & 0.009 & $<0.001$ & $<0.001$ \\
\hline
\end{tabular}

${ }^{1}$ Primary producers: phytoplankton, macrophytes, and terrestrial plants

${ }^{2}$ Herbivores/omnivores: annelids, bivalves, certain crustaceans, echinoderms, zooplankton, terrestrial insects, and certain terrestrial mammals

${ }^{3}$ Carnivores: cephalopods, certain crustaceans, fish, marine mammals, and certain terrestrial mammals 
Table 3. Fatty acid content ( $\%$ total fatty acids) of marine organisms in three latitudinal zones: polar $\left(90-60^{\circ} \mathrm{N}\right.$ and $\left.\mathrm{S}\right)$, temperate $\left(60-30^{\circ} \mathrm{N}\right.$ and $\mathrm{S})$, and tropical $\left(30^{\circ} \mathrm{N}\right.$ to $\left.30^{\circ} \mathrm{S}\right)$. Different superscripts, in the same column (i.e. for each fatty acid), indicate significant differences among latitudinal zones.

\begin{tabular}{|c|c|c|c|c|c|c|c|c|c|c|c|}
\hline Latitudinal zone & ALA & LNA & ARA & EPA & DHA & $\sum$ SFA & $\sum$ MUFA & $\sum$ PUFA & $\sum$ n-3 FA & $\sum$ n-6 FA & DHA/EPA \\
\hline Polar $(\mathrm{n}=372)$ & $1.7 \pm 0.2$ & $2.1 \pm 0.2$ & $1.9 \pm 0.3^{\mathrm{a}}$ & $13.6 \pm 0.5^{\mathrm{a}}$ & $10.5 \pm 0.4^{\mathrm{a}}$ & $22.2 \pm 0.5^{\mathrm{a}}$ & $39.9 \pm 0.9^{\mathrm{a}}$ & $42.8 \pm 0.8^{\mathrm{a}}$ & $24.5 \pm 0.7^{\mathrm{a}}$ & $4.1 \pm 0.3^{\mathrm{a}}$ & $1.9 \pm 0.2$ \\
\hline Temperate $(n=1217)$ & $2.6 \pm 0.4$ & $2.6 \pm 0.1$ & $3.8 \pm 0.1^{\mathrm{b}}$ & $12.3 \pm 0.2^{\mathrm{b}}$ & $9.7 \pm 0.3^{\mathrm{a}}$ & $30.1 \pm 0.4^{\mathrm{b}}$ & $26.3 \pm 0.4^{\mathrm{b}}$ & $40.1 \pm 0.4^{\mathrm{b}}$ & $24.6 \pm 0.6^{\mathrm{a}}$ & $6.4 \pm 0.2^{b}$ & $1.5 \pm 0.1$ \\
\hline Tropical $(n=263)$ & $2.3 \pm 0.3$ & $3.1 \pm 0.2$ & $4.6 \pm 0.3^{c}$ & $6.9 \pm 0.4^{\mathrm{c}}$ & $8.3 \pm 0.6^{b}$ & $35.1 \pm 0.8^{\mathrm{c}}$ & $26.3 \pm 0.7^{b}$ & $34.7 \pm 0.8^{\mathrm{c}}$ & $18.1 \pm 0.7^{\mathrm{b}}$ & $7.7 \pm 0.4^{\mathrm{c}}$ & $2.5 \pm 0.3$ \\
\hline
\end{tabular}


Table 4. Fatty acid content ( $\%$ total fatty acid; mean \pm standard error) in marine and terrestrial organisms, with results of ANOVA

\begin{tabular}{|c|l|l|c|c|c|c|}
\hline \multirow{2}{*}{ Fatty acid } & \multirow{2}{*}{ Marine } & Terrestrial & \multicolumn{2}{|c|}{ Biome } & \multicolumn{2}{c|}{ Trophic level } \\
\hline & & & F-stat & p-value & F-stat & p-value \\
\hline ALA & $2.3 \pm 0.3$ & $9.6 \pm 0.5$ & 177 & $<0.001$ & 20.1 & $<0.001$ \\
\hline LNA & $2.5 \pm 0.1$ & $23.6 \pm 0.6$ & 2121 & $<0.001$ & 272 & $<0.001$ \\
\hline ARA & $3.4 \pm 0.1$ & $7.2 \pm 0.6$ & 52.2 & $<0.001$ & 37.1 & $<0.001$ \\
\hline EPA & $11.7 \pm 0.1$ & $0.9 \pm 0.1$ & 405 & $<0.001$ & 71.5 & $<0.001$ \\
\hline DHA & $9.2 \pm 0.2$ & $2.1 \pm 0.1$ & 167 & $<0.001$ & 329 & $<0.001$ \\
\hline$\sum$ SFA & $29.8 \pm 0.3$ & $31.6 \pm 0.6$ & 0.05 & 0.819 & 48.6 & $<0.001$ \\
\hline$\sum$ MUFA & $28.8 \pm 0.3$ & $31.8 \pm 0.6$ & 101 & $<0.001$ & 210 & $<0.001$ \\
\hline$\sum$ PUFA & $38.9 \pm 0.3$ & $35.8 \pm 0.7$ & 43.3 & $<0.001$ & 86.5 & $<0.001$ \\
\hline$\sum$ n-3 FA & $23.2 \pm 0.4$ & $6.3 \pm 0.3$ & 202 & $<0.001$ & 12.3 & 0.009 \\
\hline$\sum$ n-6 FA & $5.7 \pm 0.2$ & $17.6 \pm 0.7$ & 482 & $<0.001$ & 53.2 & $<0.001$ \\
\hline
\end{tabular}
(model 2; biome and trophic level as categorical variables).

\footnotetext{
${ }^{1}$ Sum of n-3 $=$ ALA + EPA + DHA

${ }^{2}$ Sum of $n-6=$ LNA + ARA
} 
Table 5. ANOVA models used to analyze fatty acid content ( $\%$ total fatty acids $)$ in marine and terrestrial organisms.

\begin{tabular}{|c|c|c|c|}
\hline Model number & Model type & Variables & Objective \\
\hline 1 & ANOVA & $\begin{array}{c}\text { Biome (categorical) } \\
\text { Taxonomic Group (categorical) } \\
\text { Biome x Group Interaction }\end{array}$ & $\begin{array}{l}\text { To determine the effect of biome, taxonomic group, and their } \\
\text { interaction on fatty acid content in all organisms }\end{array}$ \\
\hline 2 & ANOVA & $\begin{array}{c}\text { Biome (categorical) } \\
\text { Trophic level (categorical) }\end{array}$ & $\begin{array}{l}\text { To determine if fatty acid content in organisms depends on } \\
\text { increasing trophic level in either biome }\end{array}$ \\
\hline 3 & ANOVA & $\begin{array}{l}\text { Taxonomic group (categorical) } \\
\text { Latitudinal zone (categorical) }\end{array}$ & $\begin{array}{l}\text { To determine the effect of taxonomic group and latitudinal zone } \\
\text { on the fatty acid content of marine organisms }\end{array}$ \\
\hline 4 & ANOVA & $\begin{array}{l}\text { Latitudinal zone (categorical) } \\
\text { Trophic level (categorical) }\end{array}$ & $\begin{array}{l}\text { To determine if fatty acid content in marine organisms depends } \\
\text { on increasing trophic level among latitudinal zones }\end{array}$ \\
\hline 5 & ANOVA (nested) & $\begin{array}{l}\text { Trophic level (categorical) } \\
\text { Taxonomic group (nested factor) }\end{array}$ & $\begin{array}{c}\text { To determine whether trophic level or taxonomic group (within } \\
\text { each trophic level) are more important in predicting FA content } \\
\text { in marine organisms }\end{array}$ \\
\hline 6 & ANOVA (nested) & $\begin{array}{l}\text { Taxonomic group (categorical) } \\
\text { Latitudinal zone (nested factor) }\end{array}$ & $\begin{array}{l}\text { To determine whether the fatty acid content in marine } \\
\text { organisms differs depending on latitudinal zone within each } \\
\text { taxonomic group }\end{array}$ \\
\hline
\end{tabular}

${ }^{1}$ In this model, we were not interested in the distinct taxonomic group, but rather the difference among random groups within each trophic level. 


\section{References}

Ackman, R.G., Tocher, C.S., and McLachlan, J. 1968. Marine phytoplankter fatty acids. J. Fish Res. Board Canada. 25: 1603-1620.

Ahlgren, G., Vrede, T., and Goedkoop, W. 2009. Fatty acid ratios in freshwater fish, zooplankton, and zoobenthos - Are there specific optima? In Lipids in Aquatic Ecosystems. Edited by M.T Arts, M.T. Brett, and M.J. Kainz. Springer, New York. pp. 147-168.

Arts, M.T., Ackman, R.G., and Holub, B.J. 2001. 'Essential fatty acids' in aquatic ecosystems: a crucial link between diet and human health and evolution. Can. J. Fish Aquat. Sci. 58: 122-137.

Arts, M.T., Brett, M.T., and Kainz, M.J. 2009. Lipids in aquatic ecosystems. Springer, New York.

Arts, M.T., and Kohler, C.C. 2009. Health and condition in fish: the influence of lipids on membrane competency and immune response. In Lipids in Aquatic Ecosystems. Edited by M.T. Arts, M.T. Brett, and M.J. Kainz. Springer, New York. pp. 237-256.

Bazinet, R.P., and Laye, S. 2014. Polyunsaturated fatty acids and their metabolites in brain function and disease. Nature Rev. Neurosci. 15: 771-785.

Bermúdez R., Feng Y., Roleda M.Y., Tatters A.O., Hutchins D.A., Larsen T., Boyd P.W., Hurd C.L., Riebesell U. and M. Winder. 2015. Long-Term conditioning to elevated pCO2 and warming influences the fatty and amino acid composition of the diatom Cylindrotheca fusiformis. PLoS ONE 10(5): e0123945.

Boelen, P., van Dijk, R., Damste, J.S.S., Rijpstra, W.I.C., and Burna, A.G.J. 2013. On the potential application of polar and temperate marine microalgae for EPA and DHA production. AMB Express. 3:26. doi: 10.1186/2191-0855-3-26

Bray, J.R., and Curtis, J.T. 1957. An ordination of the upland forest communities of southern Wisconsin. Ecol. Monogr. 27: 325-349.

Brenna, J.T., Salem, N., Sinclair, A., and Cunanne, S.C. 2009. $\alpha$-Linolenic acid supplementation and conversion to n-3 long-chain polyunsaturated fatty acids in humans. Prostag. Leukotr. Ess. 80: 85-91.

Brenna, J.T., and Carlson, S.E. 2014. Docosahexaenoic acid and human brain development: evidence that a dietary supply is needed for optimal development. J. Human Evol. 77: 99106.

Brett, M.T., and Müller-Navarra, D.C. 1997. The role of highly unsaturated fatty acids in aquatic foodweb processes. Freshwater Biol. 38: 483-499. 
Brett, M.T., Müller-Navarra, D.C., and Persson, J. 2009. Crustacean zooplankton fatty acid composition. In Lipids in Aquatic Ecosystems. Edited by M.T. Arts, M.T. Brett, and M.J. Kainz. Springer, New York. pp. 115-146.

Broadhurst, C.L., Wang, Y., Crawford, M.A., Cunnane, S.C., Parkington, J.E., and Schmidt, W.F. 2002. Brain-specific lipids from marine, lacustrine, or terrestrial food resources: potential impact on early African Homo sapiens. Comp. Biochem. Physiol. B. 131: 653673.

Brockerhoff, H., Ackman, R.G., and Hoyle, R.J. 1963. Specific distribution of fatty acids in marine lipids. Archives Biochem. Biophys. 100: 9-12.

Budge, S.M., Iverson, S.J., Bowen, D., and Ackman, R.G. 2002. Among- and within species variability in fatty acid signatures of marine fish and invertebrates on the Scotian Shelf, Georges Bank, and southern Gulf of St. Lawrence. Can. J. Fish. Aquat. Sci. 59: 886-898.

Budge, S.M., Iverson, S.J., and Koopman, H.N. 2006. Studying trophic ecology in marine ecosystems using fatty acids: A primer on analysis and interpretation. Mar. Mam. Sci. 22: 759-801.

Calder, P.C. 2015. Marine omega-3 fatty acids and inflammatory processes: effects, mechanisms and clinical relevance. Biochim. Biophys. Acta, 1851: 469-484.

Cheung, W.W.L., Lam, V.W.Y., Sarmiento, J.L., Kearney, K., Watson, R., and Pauly, D. 2009. Projecting global marine biodiversity impacts under climate change scenarios. Fish and Fisheries. 10: 235-251.

Clarke, K., and Warwick, R. 2001. Change in marine communities: an approach to statistical analyses and interpretation. Primer-E Ltd., Plymouth, UK.

Clarke, A. 2003. Costs and consequences of evolutionary temperature adaptation. Trends Ecol. Evol. 18: 573-581.

Cook, H.W., and McMaster, C.R. 2004. Fatty acid desaturation and chain elongation in eukaryotes. In Biochemistry of lipids, lipoproteins and membranes. New Comprehensive Biochemistry. Edited by D.E. Vance and J.E. Vance. Elsevier. Amsterdam, the Netherlands. pp. 181-204.

Cossins, A.R., and Prosser, C.L. 1978. Evolutionary adaptation to temperature. Proc. Natl. Acad. Sci. 75: 2040-2043.

Dalsgaard, J., St. John, M., Kattner, G., Müller-Navarra, D., and Hagen, W. 2003. Fatty acid trophic markers in the pelagic marine food environment. Adv. Mar. Biol. 46: 225-340.

Domenichiello, F., Kitson, A.P. and Bazinet, R.P. 2015. Is docosahexaenoic acid synthesis from a-linolenic acid sufficient to supply the adult brain? Prog. Lipid Res. 59: 54-66.

Doney, S., Fabry, V., Feely, R., and Kleypas, J. 2009. Ocean acidification: the other CO2 problem. Annu. Rev. Mar. Sci. 1, 169-192. 
Dubois, V., Breton, S., Linder, M., Fanni, J., Parmentier, M. 2007. Fatty acid profiles of 80 vegetable oils with regard to their nutritional potential. Eur. J. Lipid. Sci. Technol. 109: $710-732$.

Emery, J.A., Norambuena, F., Trushenski, J., and Turchini, G.M. 2016. Uncoupling EPA and DHA in fish nutrition: Dietary demand is limited in Atlantic salmon and effectively met by DHA alone. Lipids. doi:10.1007/s11745-016-4136-y

Galloway, A.W.E., and Winder, M. 2015. Partitioning the relative importance of phylogeny and environmental conditions on phytoplankton fatty acids. PLoS One. 10: e0130053.

Galván, I., Naudí, A., Erritzøe, J., Møller, A.P., Barja, G., Pamplona, R. 2015. Long lifespans have evolved with long and monounsaturated fatty acids in birds. Evolution 69:27762784.

Gamito, R., Costa, M.J., and Cabral, H.N. 2015. Fisheries in a warming ocean: trends in fish catches in the large marine ecosystems of the world. Reg. Environ. Change. 15: 57-65.

Gaston, K.J. 2003. The structure and dynamics of geographic ranges. Oxford University Press, New York, NY, USA.

Gladyshev, M.I., Semenchenko, V.P., Dubovskaya, O.P., Fefilova, E.B., Makhutova, O.N., Buseva, Z.F., Sushchik, N.N., Razlutskij, V.I., Lepskaya, E.V., Baturina, M.A., Kalachova, G.S., and Kononova, O.N. 2011. Effect of temperature on contents of essential highly unsaturated fatty acids in freshwater zooplankton. Limnologica. 41: 339347.

Gladyshev, M.I., Sushchika, N.N., and Makhutova, O.N. 2013. Production of EPA and DHA in aquatic ecosystems and their transfer to the land. Prostaglandins Other Lipid. Mediat. 107: 117-126.

Glencross, B.D., De Santis, C.D., Bicskei, B., Taggart, J.B., Bron, J.E, Betancor, M.B., and Tocher, D.R. 2015. A comparative analysis of the response of the hepatic transcriptome to dietary docosahexaenoic acid in Atlantic salmon (Salmo salar) post-smolts. BMC Genomics. 16: 684 doi:10.1186/s12864-015-1810-z

Greenacre, M., and Primicero, R. 2013. Multivariate analysis of ecological data. Fundación BBVA. Bilbao Spain. pp. 279-281.

Guglielmo, C. G. 2010. Move that fatty acid: Fuel selection and transport in migratory birds and bats. Integr. Comp. Biol. 50: 336-345.

Guschina, I.A., and Harwood, J.L. 2006. Mechanisms of temperature adaptation in poikilotherms. FEBS Lett. 580: 5477-5483.

Hartwich, M., Martin-Creuzburg, D., Wacker, A. 2013. Seasonal changes in the accumulation of polyunsaturated fatty acids in zooplankton. J. Plankton Res. 35: 121-134. 
Hazel, J.R. 1995. Thermal adaptation in biological membranes: is homeoviscous adaptation the explanation? Annu. Rev. Physiol. 57: 19-42.

Hixson, S.M., and Arts, M.T. 2016. Climate warming is predicted to reduce omega-3, longchain, polyunsaturated fatty acid production in phytoplankton. Global Change Biol. 22:8 doi: $10.1111 / \mathrm{gcb} .13295$

Hixson, S.M., Sharma, B, Kainz, M.J., Wacker, A., and Arts, M.T. 2015. Production, distribution, and abundance of long-chain omega-3 polyunsaturated fatty acids: A fundamental dichotomy between freshwater and terrestrial ecosystems. Environ. Rev. 23: 414-424.

Hoegh-Guldberg, O., and Bruno, J.F. 2010. The impact of climate change on the world's marine ecosystems. Science. 5985: 1523-1528.

Hong, S., Gronert, K., Devchand, P.R., Moussignac, R.L., and Serhan, C.N. 2003. Novel docosatrienes and 17S-resolvins generated from docosahexaenoic acid in murine brain, human blood, and glial cells. Autacoids in anti-inflammation. 278: 14677-14687.

Iverson, S.J., Frost, K.J., and Lowry, L.F. 1997. Fatty acid signatures reveal fine scale structure of foraging distribution of harbor seals and their prey in Prince William Sound, Alaska. Mar. Ecol. Prog. Ser. 151: 255-271.

Iverson, S.J., Field, C., and Bowen, W.D., and Blanchard, W. 2004. Quantitative fatty acid signature analysis: a new method of estimating predator diets. Ecol. Monogr. 74: 211235.

Iverson, S.J. 2009. Tracing aquatic food webs using fatty acids: from qualitative indicators to quantitative determination. In Lipids in Aquatic Ecosystems. Edited by Arts, M.T., Brett, M.T., and Kainz, M.J. Springer, New York. pp. 281-307.

Kainz, M.J., Arts, M.T., and Mazumber, A. 2004. Essential fatty acids in the planktonic food web and their ecological role for higher trophic levels. Limnol. Oceanograph. 49: 17841793.

Kattner, G., and Hagen, W. 2009. Lipids in marine copepods: Latitudinal characteristics and perspective to global warming. In Lipids in Aquatic Ecosystems. Edited by M.T. Arts, M.T. Brett, and M.J. Kainz. Springer, New York. pp. 257-280.

Kelly, J.R.., and Scheibling, R.E. 2012. Fatty acids as dietary tracers in benthic food webs. Mar. Ecol. Prog. Ser. 446: 1-22.

Kolakowska, A., Domiszewski, Z., and Bienkiewicz, G. 2006. Effects of biological and technological factors on the utility of fish as a source of n-3 PUFA. In Omega-3 Fatty Acid Research. Edited by M.C Teale. Nova Science Publishers Inc. New York. pp. 83107. 
Koussoroplis, A., Lemarchand, C., Bec, A., Desvilettes, C., Amblard, C., Fournier, C., Berny, P., and Bourdier, G. 2008. From aquatic to terrestrial food webs: decrease of the docosahexaenoic acid/linoleic acid ratio. Lipids, 43: 461-466.

Lands, W.E.M. 1982. Biochemical observations on long-chain fatty acids from fish oil and their effect on prostaglandin synthesis in animals and humans. In Nutritional Evaluation of Long Chain Fatty Acids in Fish Oil. Edited by S.M. Barlow, and M.E. Stansby. Academic Press, London. pp. 25-88.

Lane, R.L., Trushenski, J.T., and Kohler, C.C. 2006. Modification of fillet composition and evidence of differential fatty acid turnover in sunshine bass Morone chrysops $\times M$. saxatilis following change in dietary lipid source. Lipids. 41: 1029-1038.

Maillet, D., and J. M. Weber. 2006. Performance-enhancing role of dietary fatty acids in a long distance migrant shorebird: the semi palmated sandpiper. J. Exp. Biol. 209: 2686-2695

Makhutova, O.N., Sushchik, N.N., Gladyshev, M.I., Ageev, A.V., Pryanichnikova, E.G., and Kalachova, G.S. 2011. Is the fatty acid composition of freshwater zoobenthic invertebrates controlled by phylogenetic or trophic factors? Lipids. 46: 709-721.

Mourente, G., Lubián, L.M., and Odriozola, J.M.1990. Total fatty acid composition as a taxonomic index of some marine microalgae used as food in marine aquaculture. Hydrobiologia. 203: 147-154.

Murray, D.S., Hager, H.H., Tocher, D.R., and Kainz, M.J. 2014. Effect of partial replacement of dietary fish meal and oil by pumpkin kernel cake and rapeseed oil on fatty acid composition and metabolism in Arctic charr (Salvelinus alpinus). Aquaculture. 431: 8591.

Parrish, C.C., Yang, Z., Lau, A., and Thompson, R.J. 1996. Lipid composition of Yoldia hyperborea (Protobranchia), Nephthys ciliate (Nephthydae) and Artacama proboscidea (Terebellidae) living at sub-zero temperatures. Comp. Biochem. Physiol. B. 114: 59-67

Parrish, C.C. 2009. Essential fatty acids in aquatic food webs. In Lipids in Aquatic Ecosystems. Edited by M.T. Arts, M.T. Brett, and M.J. Kainz. Springer. New York, pp. 309-326.

Parrish, C.C. 2013. Lipids in marine ecosystems. [Online]. ISRN Oceanography. doi: $10.5402 / 2013 / 604045$.

Parrish, C.C., Pethybridge, H., Young, J.W., and Nichols, P.D. 2015. Spatial variation in fatty acid trophic markers in albacore tuna from the southwestern Pacific Ocean - A potential 'tropicalization' signal. Deep Sea Res. II. 113: 199-207.

Persson, J., and Vrede, T. 2006. Polyunsaturated fatty acids in zooplankton: variation due to taxonomy and trophic position. Freshwater Bio. 51: 887-900.

Pethybridge, H.R., Parrish, C.C., Morrongiello, J., Young, J.W, Farley, J.H., Gunasekera, R.M., et al. 2015. Spatial patterns and temperature predictions of tuna fatty acids: Tracing essential nutrients and changes in primary producers. PLoS ONE. 10(7): e0131598. 
Polovina, J.J., Howell, E.A., and Abecassis, M. 2008. Ocean's least productive waters are expanding. Geophys. Res. Lett. 35: L03618

Rombenso, A.N., Trushenski, J.T., Jirsa, D., and Drawbridge, M. 2016. Docosahexaenoic acid (DHA) and arachidonic acid (ARA) are essential to meet LC-PUFA requirements of juvenile California Yellowtail (Seriola dorsalis) Aquaculture. 463: 123-134.

Schlechtriem, C., Arts, M.T., and Zellmer, I.D. 2006. Effect of temperature on the fatty acid composition and temporal trajectories of fatty acids in fasting Daphnia pulex (Crustacea, Cladocera). Lipids. 41: 397-400.

Sharma, P., Kumar, V., Sinha, A.K., Ranjan, J., Kithsiri, H.M.P., and Venkateshwarlu, G. 2010. Comparative fatty acid profiles of wild and farmed tropical freshwater fish rohu (Labeo rohita). Fish Physiol. Biochem. 36: 411-417.

Smetacek, V., and Nicol, S. 2005. Polar ocean ecosystems in a changing world. 437: 362-368.

Skjervold, H. 1992. Lifestyle diseases and the human diet. How should the new discoveries influence the food production? In: The Journal of Dairy Industry of Norway. Norway. p 48.

Simopoulos, A.P. 2011. Evolutionary aspects of diet: the omega-6/omega-3 ratio and the brain. Mol. Neurobiol. 44: 203-215.

Sinensky, M. 1974. Homeoviscous adaptation - Homeostatic process that regulates viscosity of membrane lipids in Escherichia coli. Proc. Natl. Acad. Sci: 71: 522-525.

Sperfeld, E., and Wacker, A. 2012. Temperature affects the limitation of Daphnia magna by eicosapentaenoic acid, and the fatty acid composition of body tissue and eggs. Freshwater Biol. 57: 497-508.

Stachowicz, J.J., Terwin, J.R., Whitlatch, R.B, and Osman, R.W. 2002. Linking climate change and biological invasions: Ocean warming facilitates nonindigenous species invasions. Proc. Natl. Acad. Sci. 99: 15497-15500.

Swanson, D., Block, R., and Mousa, S.A. 2012. Omega-3 fatty acids EPA and DHA: Health benefits throughout life. Adv. Nutr. 3: 1-7.

Taipale, S., Strandberg, U., Peltomaa, E., Galloway, A.W.E., Ojala, A., and Brett, M. 2013. Fatty acid composition as biomarkers of freshwater microalgae: analysis of 37 strains of microalgae in 22 genera and in seven classes. Aquat. Microb. Ecol. 71: 165-178.

Thomas, D.N., Dieckmann, G.S. 2002. Antarctic sea ice- a habitat for extremophiles. Science. 295: 641-644.

Tocher, D.R. 2015. Omega-3 long-chain polyunsaturated fatty acids and aquaculture in perspective. Aquaculture. 449: 94-107.

Tocher, D.R., Dick, J.R., MacGlaughlin, P., Bell, J.G. 2006. Effect of diets enriched in Delta 6 desaturated fatty acids (18:3n-6 and 18:4n-3), on growth, fatty acid composition and 
highly unsaturated fatty acid synthesis in two populations of Arctic charr (Salvelinus alpinus L.). Comp. Biochem. Physiol. B. 144: 245-253.

Torres-Ruiz, M., Wehr, J.D., Perrone, A.A. 2010. Are net-spinning caddisflies what they eat? An investigation using controlled diets and fatty acids. J. N. Am. Benthol. Soc. 29: 803-813.

Trushenski, J., Schwarz, M., Bergman, A., Rombenso, A., and Delbos, B. 2012. DHA is essential, EPA appears largely expendable, in meeting the $n-3$ long-chain polyunsaturated fatty acid requirements of juvenile cobia Rachycentron canadum. Aquaculture 326-329: 81-89.

Turcotte, C., Chouinard, F., Lefebvre, J.S., and Flamand, N. 2015. Regulation of inflammation by cannabinoids, the endocannabinoids 2-arachidonylglycerol and arachidonylathanolamide, and their metabolites. J. Leukoc. Biol. 97: 1049-1070.

Twining, C.W., Brenna, J.T., Hairston, N.G., and Flecker, A.S. 2016. Highly unsaturated fatty acids in nature: what we know and what we need to learn. Oikos. 125: 749-760

van Ginneken, V.J.T, Helsper, J.P.F.G., de Visser, W., van Keulen H, and Brandenburg, W.A. 2011. Polyunsaturated fatty acids in various macroalgal species from north Atlantic and tropical seas. Lipids Health Dis. 10: 104. doi: 10.1186/1476-511X-10-104

Vinagre, C., Santos, F.D., Cabral, H., and Costa, M.J. 2011. Impact of climate warming upon the fish assemblages of the Portuguese coast under different scenarios. Reg. Environ. Change. 11: 779-789.

Wacker, A., and Martin-Creuzburg, D. 2007. Allocation of essential lipids in Daphnia magna during exposure to poor food quality. Funct. Ecol. 21: 738-747

Werbrouck, E., Van Gansbeke, D., Vanreusel, A., Mensens, C., and De Troch, M. 2016. Temperature- induced changes in fatty acid dynamics of the intertidal grazer Platychelipus littoralis (Crustacea, Copepoda, Harpacticoida): insights from a short-term feeding experiment. J. Thermal Biol. 57: 44-53. 


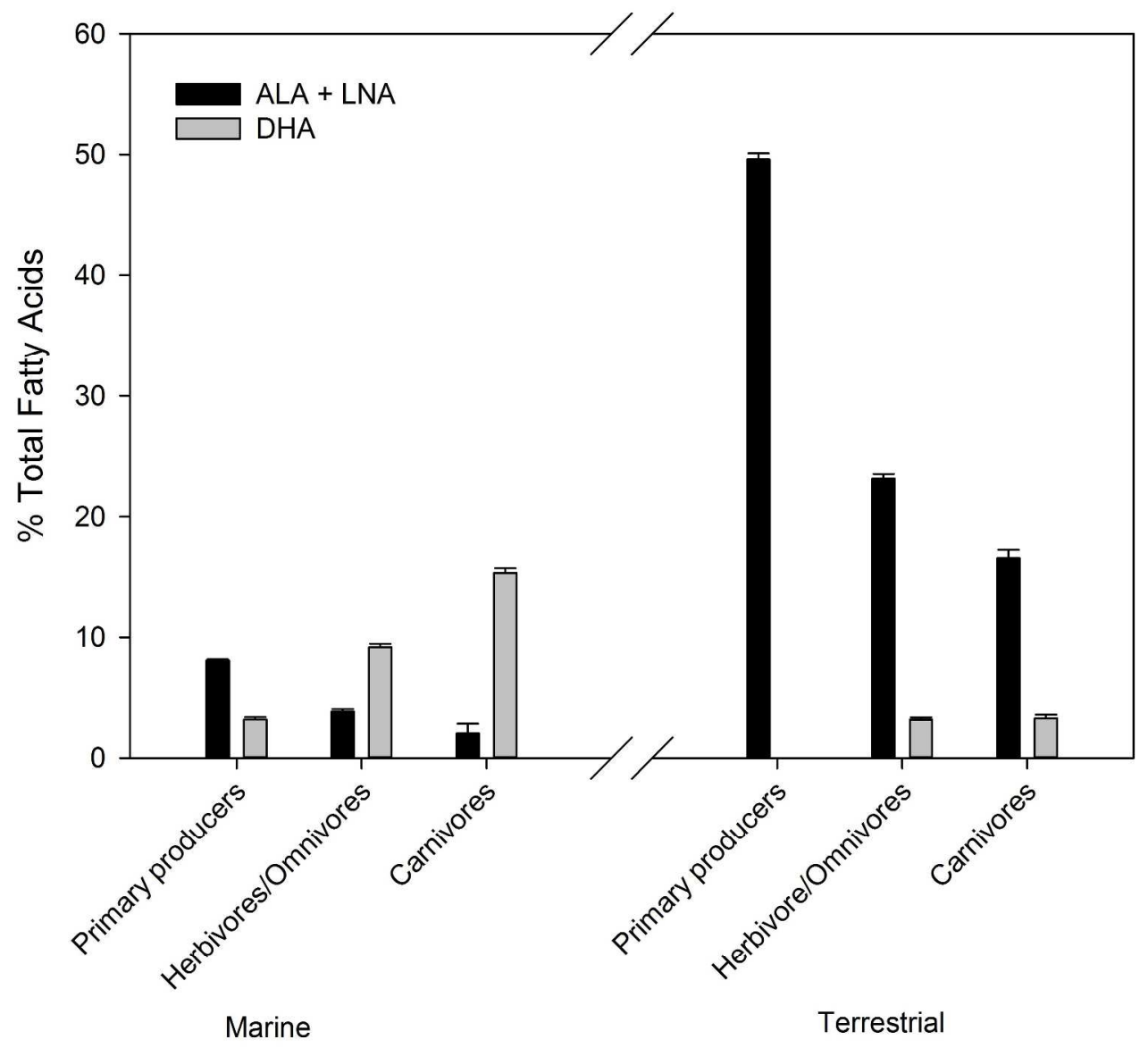

Fig. 1. Sum of ALA + LNA and DHA (mean $\pm \mathrm{SE}$ ) by trophic level in marine and terrestrial organisms. $903 \times 838 \mathrm{~mm}(96 \times 96 \mathrm{DPI})$ 

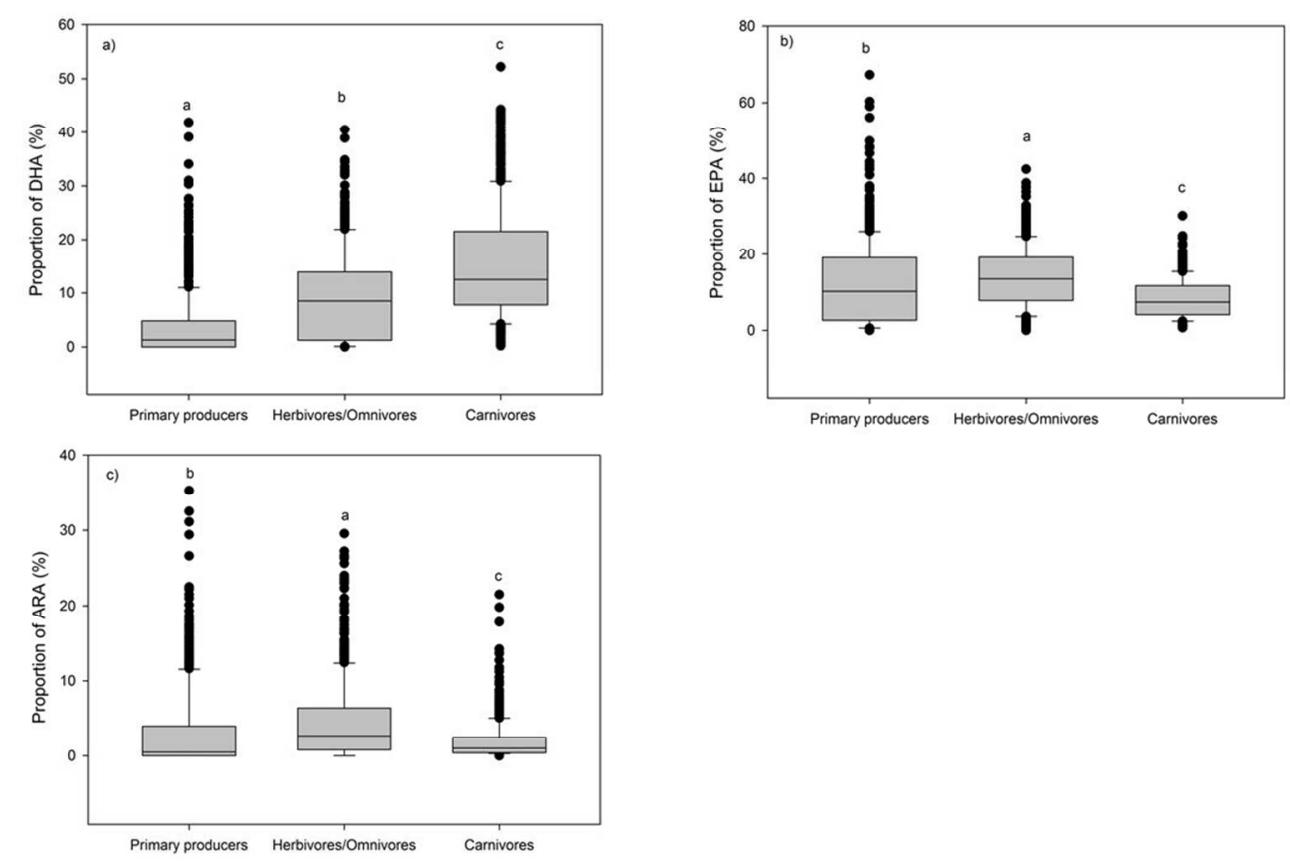

Fig. 2. Boxplots of a) DHA, b) EPA, and c) ARA levels in marine organisms by trophic level (primary producers to carnivores), where $p<0.001$ and different superscripts indicate significant differences among trophic levels for each LC-PUFA.

$288 \times 189 \mathrm{~mm}(96 \times 96 \mathrm{DPI})$ 


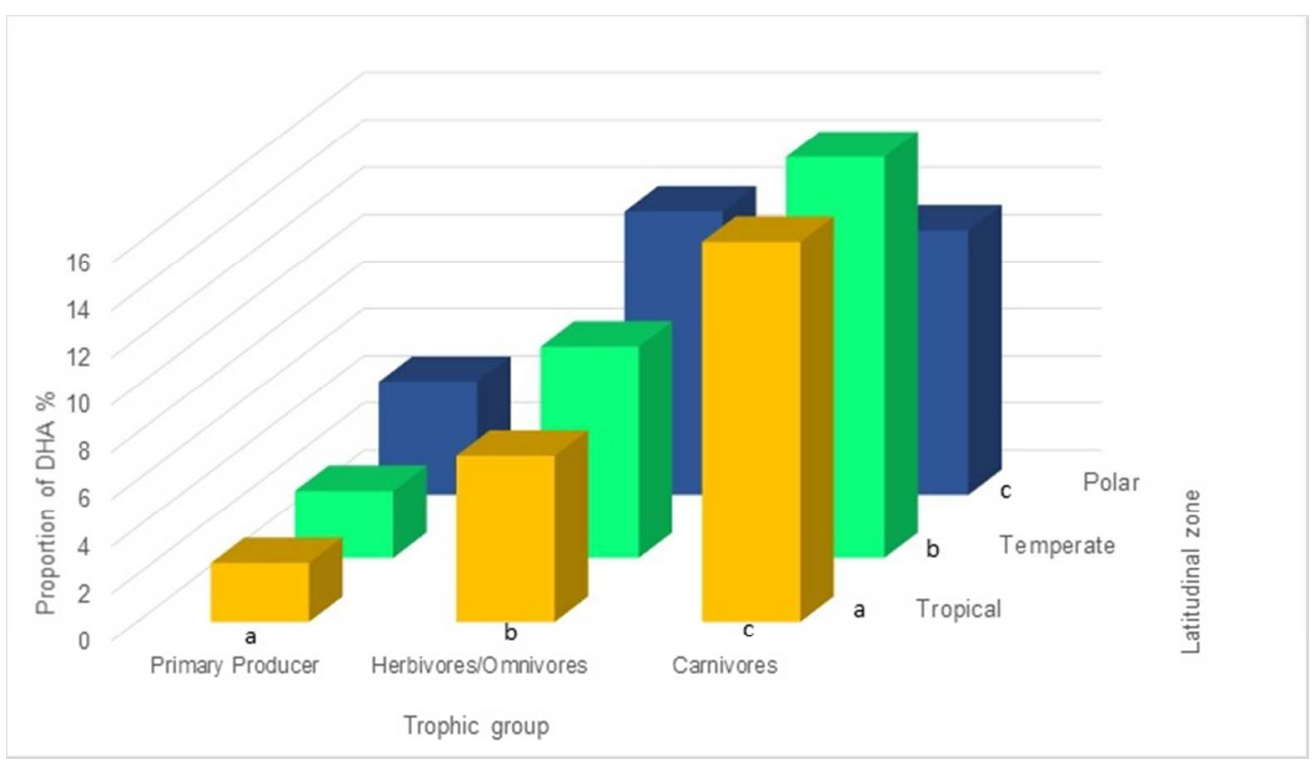

Fig. 3. Three-dimensional representation of DHA (\%) in marine organisms organized by trophic level (x-axis) and latitudinal zone (z-axis). See Table S5 for mean values ( \pm standard error) and Table S6 ANOVA model p-values. Different letters indicate significant differences among each factor, trophic level (applies to DHA in three trophic levels, regardless of latitudinal zone) and latitudinal zone (applies to DHA in three zones, regardless of trophic level).

$190 \times 108 \mathrm{~mm}(96 \times 96$ DPI $)$ 


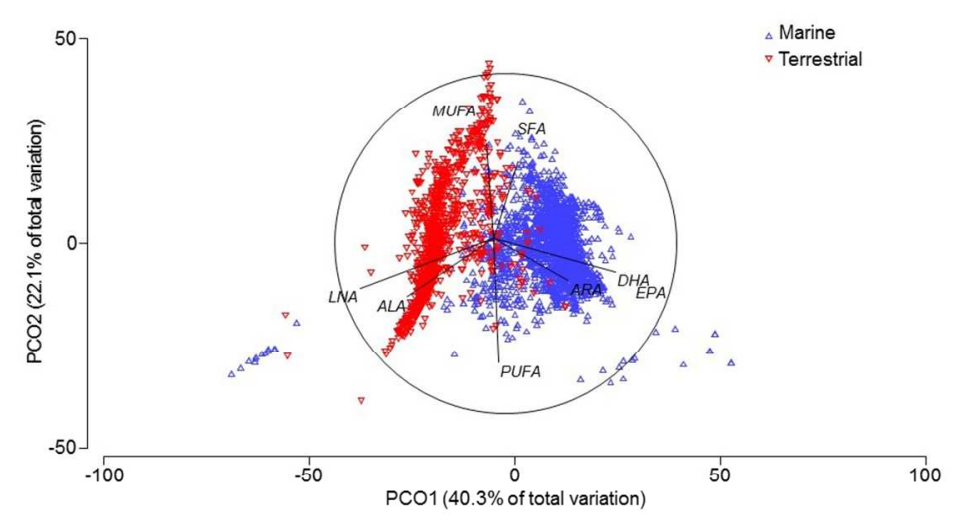

Fig. 4. Principal coordinates analysis plot of fatty acids in marine and terrestrial organisms $(n=3,072)$, using a Bray-Curtis similarity matrix (square root transformed).

$338 \times 190 \mathrm{~mm}(96 \times 96 \mathrm{DPI})$ 


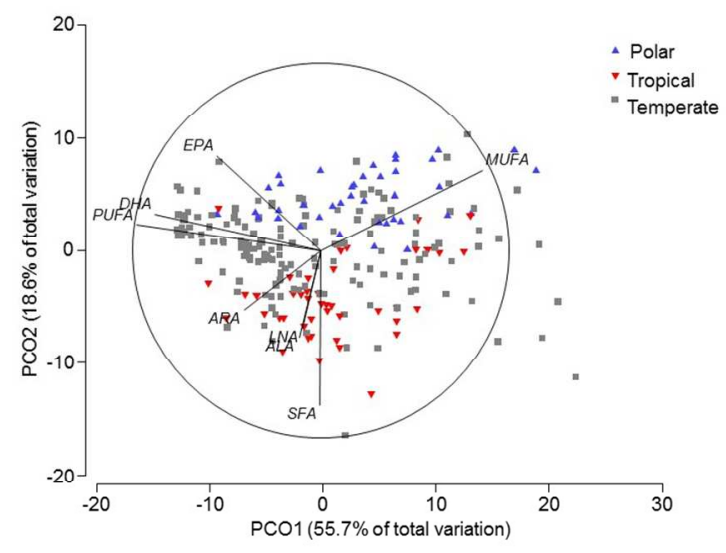

Fig. 5. Principal coordinates analysis of fatty acids in marine fish $(n=239)$ by latitudinal zone, using a BrayCurtis similarity matrix (square root transformed).

$338 \times 190 \mathrm{~mm}(96 \times 96$ DPI) 


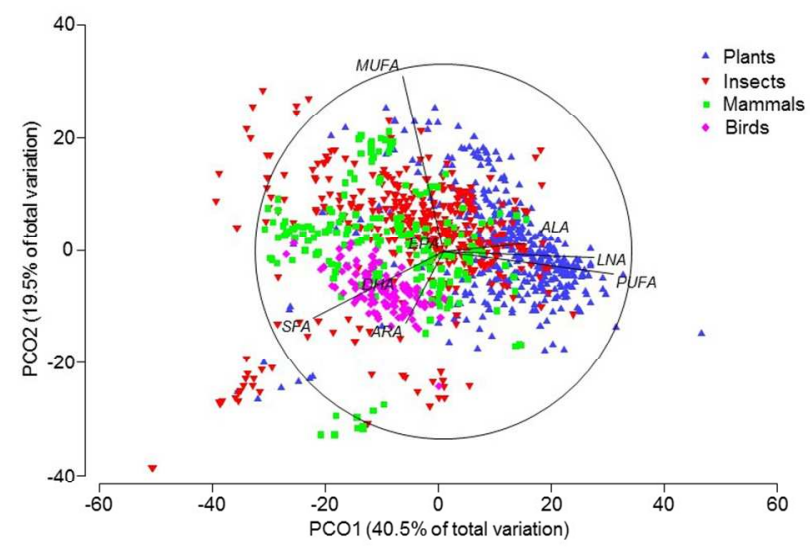

Fig. 6. Principal coordinates analysis of fatty acids in terrestrial organisms $(n=1,009)$ by taxonomic group, using a Bray-Curtis similarity matrix (square-root transformed).

$338 \times 190 \mathrm{~mm}(96 \times 96 \mathrm{DPI})$ 